\title{
Trickling Down or Fizzling Out? Economic Performance, Transfers, Inequality and Low Income
}

\author{
by
}

Myles Zyblock** and Zhengxi Lin*

11F0019MPE No. 110

ISSN:1200-5223

ISBN: 0-660-17250-X

\author{
Price: $\$ 5.00$ per issue, $\$ 25.00$ annually \\ Business and Labour Market Analysis Division \\ 24, R.H. Coats Building, Ottawa, K1A 0T6 \\ * Statistics Canada (613) 951-0830 \\ **Statistics Canada (613) 951-5132 \\ Facsimile Number: (613) 951-5403
}

December 10, 1997

We would like to thank Bower Litle for providing the internal SCF data which is used for the analysis in this paper, and Miles Corak, Michael Hatfield, Garnett Picot and Andrew Sharpe for many valuable comments and suggestions. An earlier version was presented at the international conference of the Society for the Advancement of Socio-Economics, Montreal, July 1997. We also thank the session participants for constructive comments. Errors remaining are our responsibility.

This paper represents the views of the author(s) and does not necessarily reflect the opinions of Statistics Canada. 



\section{Table of Contents}

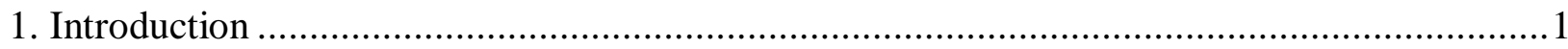

2. Economic Performance and Low Income: What Do We Know? .............................................

2.1 The American Experience.......................................................... 2

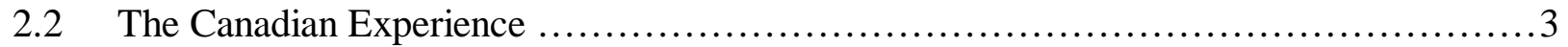

3. The Relationships between Economic Performance, Transfers and Low Income ....................... 3

3.1 Data and Definition .............................................................. 3

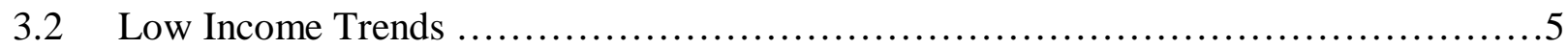

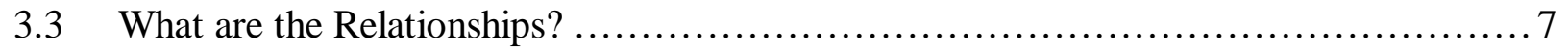

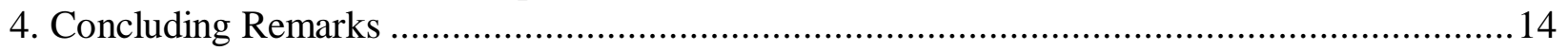

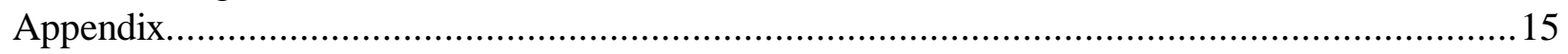

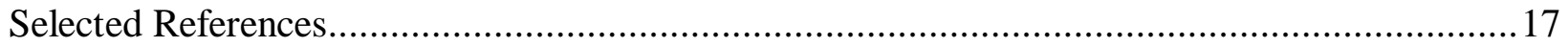





\section{Abstract}

The objectives of this paper are to determine the empirical relationships between economic performance, transfers and low income among Canadian families, and to explore whether these relationships have changed over time. Similar recent studies in the US find a weakening in the relationship between economic growth and low income reduction over the past 25 years. Using data from the Survey of Consumer Finances of Statistics Canada, we find that there is a statistically significant negative relationship between economic performance and the incidence of low income among families in Canada for the period from 1973 to 1995. Government transfers are also found to lift families above the low income threshold. These results are robust across different family types and for three different measures of low income.

We also find a weakening in the relationship between improved economic performance and low income reduction for most family types between 1973 and 1995, and for all family types after 1980. This weakening is associated with rising pre-transfer income inequality among families. Increasing inequality has also reduced the negative impact of transfers on low income rates.

\section{Key words:}

Economic performance, Transfers, Inequality, Low income JEL Classification: D31, I32 



\section{Introduction}

In principle, an improving economy can benefit those who are in a position to participate in the expansion. Those already employed can benefit through income gains as their wages are bid up by market pressures. The unemployed can benefit through job creation since the probability of finding a job increases with increased labour demand. Those out of the labour force may also find that their prospects for labour force attachment improve substantially in periods of growth. As a result, they too may gain from the employment opportunities created. In essence, the process of economic expansion in the context of income distribution research can be viewed as a process whereby the benefits of economic growth, through multiple channels or paths, 'trickle down' to the less affluent.

However, the idealistic scenarios presented above may not be the reality for the less affluent. The existence of social or economic barriers can impede the market mechanisms, or block the channels, that translate economic growth into significant reductions in low income. Examples of these barriers include the quality and nature of jobs being created, family formation and dissolution events that may disrupt attachments to the labour market, or lack of social networks. If these barriers have increased either in intensity or number, we would expect the relationship between economic expansion and low income to 'fizzle out'.

The purpose of this paper is to examine whether there is a case to be made for a 'trickling down' or 'fizzling out' hypothesis. A large body of literature on this topic exists for the US but the Canadian literature in this area is nearly non-existent. Our exploration involves a two-step process: first, to explore the empirical relationships between low income, government transfers, and economic performance. Second, to investigate whether these relationships have changed over time.

In Section 2, a brief summary of recent literature for United States is presented which points to a strong but weakening relationship between economic growth and poverty reduction. Work in this area in the Canadian context is also discussed. Section 3 explores the relationships between economic performance, transfers and low income. The results show that improved economic performance and increases in per-capita transfers are associated with a reduction in low income, and that rising inequality since the early 1980s has led to the weakening of these relationships. Finally, Section 4 concludes the paper with an overview of the findings.

\section{Economic Performance and Low Income: What Do We Know?}

How strong is the relationship between economic growth and low income reduction? Has this relationship changed over time? In an attempt to answer these questions we first turn to the body of literature that has looked at this relationship for the United States. This literature is much more advanced than that for Canada.

Analytical Studies Branch - Research Paper Series

Statistics Canada No. 11F0019MPE No. 110 


\subsection{The American Experience}

Most recent empirical studies have modeled the association between poverty rates and economic conditions in reduced form, using linear regression techniques. ${ }^{1}$ These studies often model family or individual poverty rates as a function of an economic performance variable such as the unemployment rate or GNP, a policy variable such as government transfers, and a matrix of controls for family or individual characteristics, and/or region and year effects (e.g., Tobin, 1994; Azam and Redmon, 1993; Blank and Card, 1993; Cutler and Katz, 1991; Blank and Blinder, 1986).

Common findings are that improving economic conditions or increasing government transfers, each considered in isolation, reduce the poverty rate. A model employed by Blank and Card (1993) covering the period of 1967 to 1991 estimates that a one percentage point reduction in the unemployment rate results in a 0.28 percentage point fall in the poverty rate for families. A similar multivariate model developed in Tobin (1994) estimates that a one percentage point reduction in the unemployment rate is associated with a 0.38 percentage point drop in the poverty rate for families from 1961 to 1990.

However, models relying strictly on economic variables as determinants of poverty rates have grossly underestimated observed poverty rates after 1976 and especially after 1983 . Forecast errors have averaged 0.26 percentage points over the 1984 to 1990 period, and most of the residuals were positive after 1976 (Tobin, p.159). The weakening link between economic growth and poverty reduction appears to have started in the latter part of the 1970s.

The literature places some degree of importance on the following two factors as explanations for the weakening link between economic performance and poverty reduction in the US. First, since the late 1970s, there has been a strong increase in the proportion of families whose incomes are relatively unresponsive to economic growth (e.g., lone parent families). These families have a relatively weak attachment to the labour force and do not fully participate in the gains from economic expansion (Azam and Redmon, 1993; Gottschalk and Danziger, 1985). And second, there have been changes in the structure of earnings or wages that have been disadvantageous to those most likely to be poor. Relative wage gains for less skilled workers, a usual phenomenon of past economic expansions, did not take place in the expansion of the 1980s (Cutler and Katz, 1991). Locating jobs may not be a problem for many people in the US, especially in periods of economic expansion, but finding good paying jobs may be an increasing problem. Persons at greatest risk of acquiring low-paying jobs are those with weak labour force attachment or weak skill sets.

${ }^{1}$ The United States has absolute low income thresholds that are officially recognized as poverty lines. Canada does not have an official poverty measure, although there are low income measures available such as the Low Income Measure (LIM), a purely relative income threshold; or the Low Income Cut-offs (LICOs), a hybrid measure which embodies elements of absolute and relative income thresholds since it is periodically updated for changes in the cost of living (i.e., it is periodically re-based). 


\subsection{The Canadian Experience}

Is the relationship between economic growth and the incidence of low income in Canada similar to that found in the United States? Simply put, the answer is that we do not know very much, at least for the most recent past. However, understanding whether or not those with low income continue to benefit from economic growth to the same extent as in earlier years has many important policy implications.

The Canadian literature on this topic is nearly non-existent. According to the best of our knowledge, the only Canadian study on this issue is Perron and Vaillancourt (1988), which covered the period from 1971 to 1984 and concluded that growth in GNP is the most significant factor for explaining changes in the incidence of low income. They report that a $\$ 1,000$ increase in GNP per capita (measured in 1981 dollars), is associated with a 0.95 percentage point reduction in the rate of low income. ${ }^{2}$ This remains true even after controlling for the effects of the unemployment rate (used as a proxy for labour market tightness), and government transfers per capita. Thus, growth has an important independent influence on lifting families out of low income.

They did not attempt to explore whether the beneficial impact of growth on low income has changed over time. Given the economic environment of their sample period, this type of analysis was probably not warranted. However, many well known changes have taken place on the economic and family landscape in Canada over the last fifteen years such as rising unemployment rates, and the increasing incidence of lone parenthood. Thus, the relationships that Perron and Vaillancourt documented cannot be assumed to hold today.

\section{The Relationships between Economic Performance, Transfers and Low Income}

In this section, we empirically investigate the relationships between economic performance, transfers and low income, and whether or not they have changed over time. We begin with a brief introduction of the data source and some stylized facts on low income.

\subsection{Data and Definition}

The main data used in this paper is extracted from the Survey of Consumer Finances (SCF) of Statistics Canada for the period from 1973 to 1995. SCF is an annual survey covering about 40,000 families in Canada, providing the longest available time series on family incomes. It is used to calculate low income rates, Gini coefficients, and transfers per capita.

\footnotetext{
${ }^{2}$ Perron and Vaillancourt report several variations of a reduced form model: a level specification, a semi$\log$ specification and a log-log specification. Moreover, they provide results for families of two or more persons and unattached individuals separately. We discuss their results for the linear specification of the GLS estimation procedure for families of two or more persons which accounts for regional differences and incorporates other controls such as the proportion of the population that is under 25, divorced, and over 65 . The analogous model for unattached individuals finds a much weaker relationship between economic growth and the reduction of low income and an insignificant relationship between transfers per capita and low income.
} 
Low income rates are calculated using Statistics Canada's 1992 based pre-tax Low Income Cutoffs (LICOs), updated annually for changes in the consumer price index. Three different low income thresholds are employed: 1) the proportion of the population with income less than the LICOs; 2) the proportion of the population with income less than $75 \%$ of the LICOs; and 3) the proportion of the population with income less than $50 \%$ of the LICOs. ${ }^{3}$ Using these different thresholds emphasizes varying degrees of low income and possibly captures different low income populations in terms of their socio-economic characteristics.

Reference is made to total income and market income throughout the text. ${ }^{4}$ Low income rates are calculated using the total income concept. That is, families are considered to have low income if their total income is less than the respective low income threshold. Gini coefficients presented in Section 3.4 are calculated using market income which is defined as total income less government transfers.

Employment-population ratios, unemployment rates, and GDP per capita (measured in 1992 dollars) are extracted and constructed from Statistics Canada's CANSIM database. The population of interest for this paper consists of all families of which the head is under 65 years of age. Elderly families do not rely to any considerable degree on the labour market for their primary source of income. And this contributes to the insensitivity of their low income rates to business cycle fluctuations (Figure 1). Low income rates for these families have been on a path of steady decline for over 20 years. For these reasons, we exclude elderly families from the analysis.

${ }^{3}$ The Low Income Cut-off measured in 1992 dollars for a representative family of four living in an urban center of 500,000 or more people is $\$ 30,460$. Thus, the low income threshold based on $75 \%$ and $50 \%$ of the LICOs are $\$ 22,845$ and $\$ 15,230$ respectively. Statistics Canada computes 35 different LICOs for a given year, where each threshold is conditioned on the size of the family and size of area of residence.

${ }^{4}$ Total income represents the sum on the accounts of wages and salaries, net income from selfemployment, total investment income and transfers. Transfers include the sum of the amounts on account of Old Age Security (OAS), Guaranteed Income Supplement (GIS), Canada/Quebec Pension Plan (C/QPP) benefits, Employment Insurance (EI) benefits, Child Tax benefits, refundable provincial tax credits, Goods and Services Tax (GST) credit, Social Assistance benefits and other government transfer payments. 
Figure 1

\% of Elderly Families with Income < LICO, 1973-1995

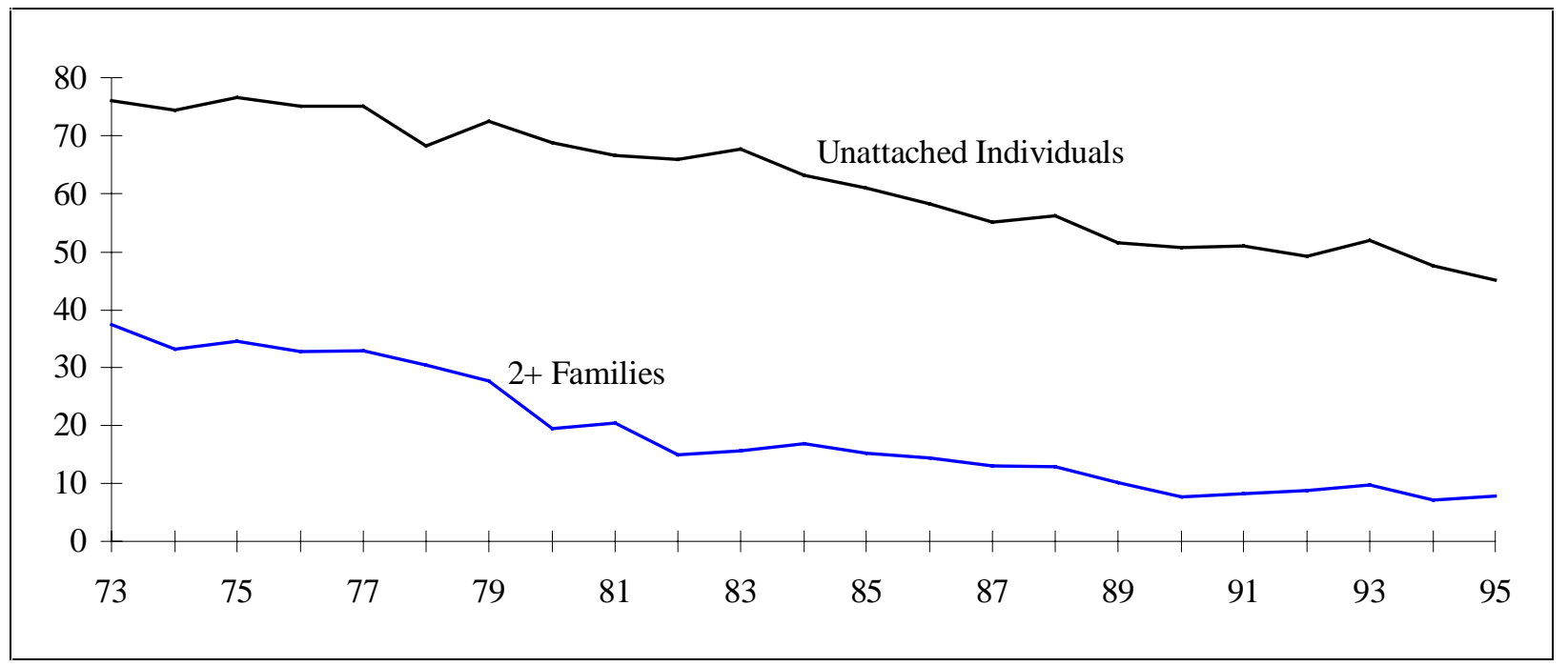

To be consistent with the family universe, transfers per capita (measured in 1992 dollars) and Gini coefficients are calculated for non-elderly families. Families are partitioned into five mutually exclusive sub-groups for a greater degree of homogeneity within groups: 1) unattached individuals; 2) couples without children $^{5}$; 3) couples with at least one child under 18; 4) lone parents with at least one child under 18; and 5) other families (for completeness), which are comprised of single parent and two parent families with no children under 18, husband and wife families with relatives other than their own children, and all remaining families not fitting into any other category (e.g., a family comprised of two brothers).

\subsection{Low Income Trends}

In Figure 2, low income rates from 1973 to 1995 are presented for each family type based on three low income thresholds. Low income among working age families in Canada closely follows the business cycle of the economy --- declining in expansions and rising during downturns. For example, low income rates declined in the economic expansion of the mid- to late-1980s, irrespective of the low income threshold or the family type. In contrast, the early 1990s recession was accompanied by rising low income for all family types.

Focusing on the trends based on LICOs, rates of low income have declined over the period from 1973 to 1995 but this decrease has varied in intensity according to family type. The smallest decrease in the rate of low income was for childless couples (from $10.6 \%$ in 1973 to $10.1 \%$ in 1995). Falling from $12.8 \%$ to $10.1 \%$ in the same period (i.e., a decrease of $21 \%$ ), other families experienced the largest decline in low income.

${ }^{5}$ Some of these families may have had children at home at one time and are now 'empty nesters'. These families may also include common law relationships. For a family to be categorized as having children, the child must be living at home. 
Figure 2

$\%$ of Non-Elderly Families with Income < LICO, < $75 \%$ of LICO and $<50 \%$ of LICO

A: Unattached Individuals

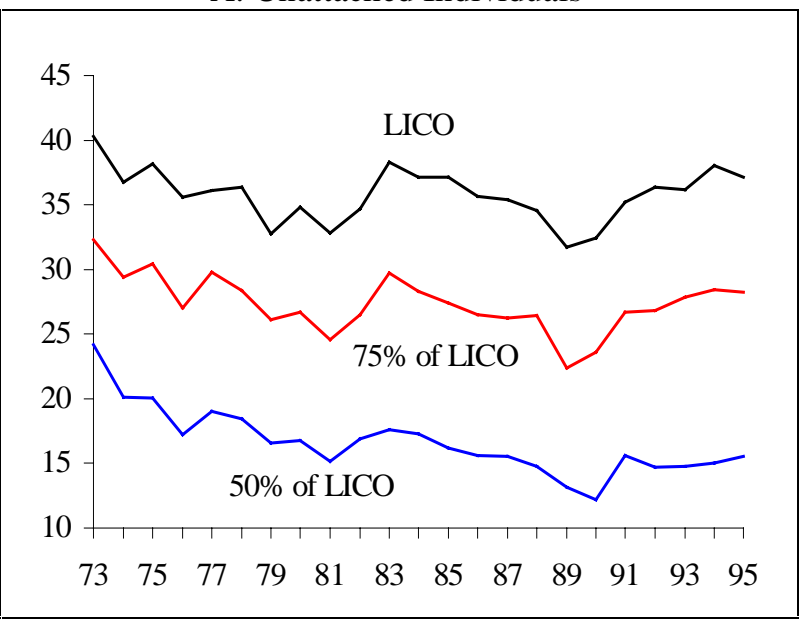

C: Couples with Dependent Children

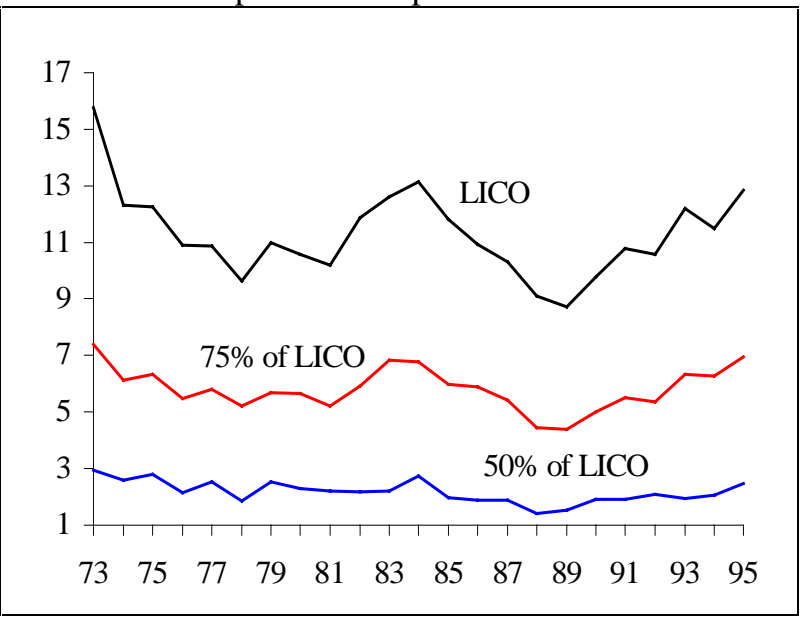

E: Other Families

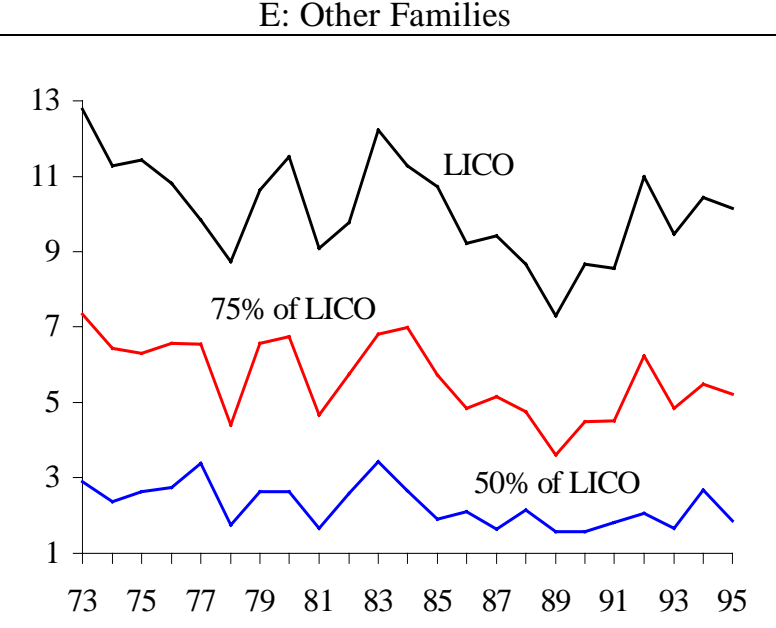

B: Couples without Children

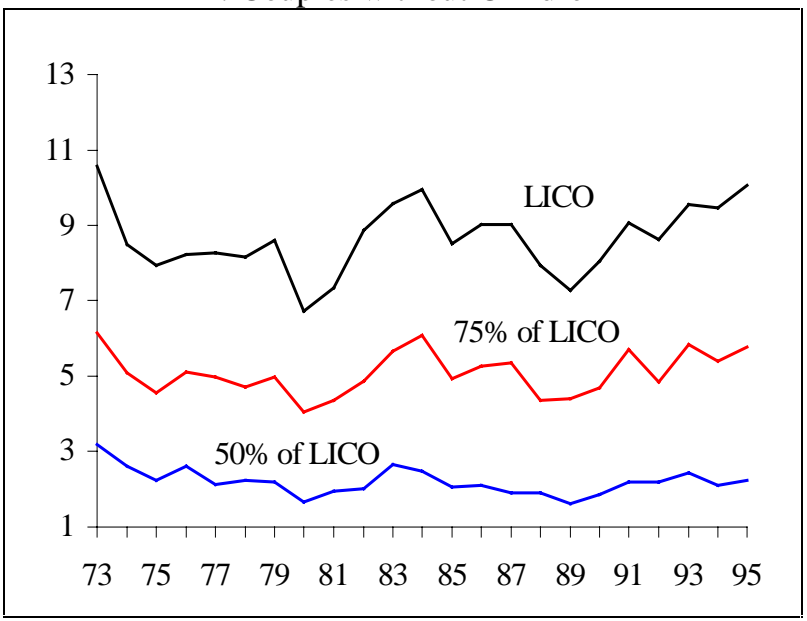

D: Lone Parents

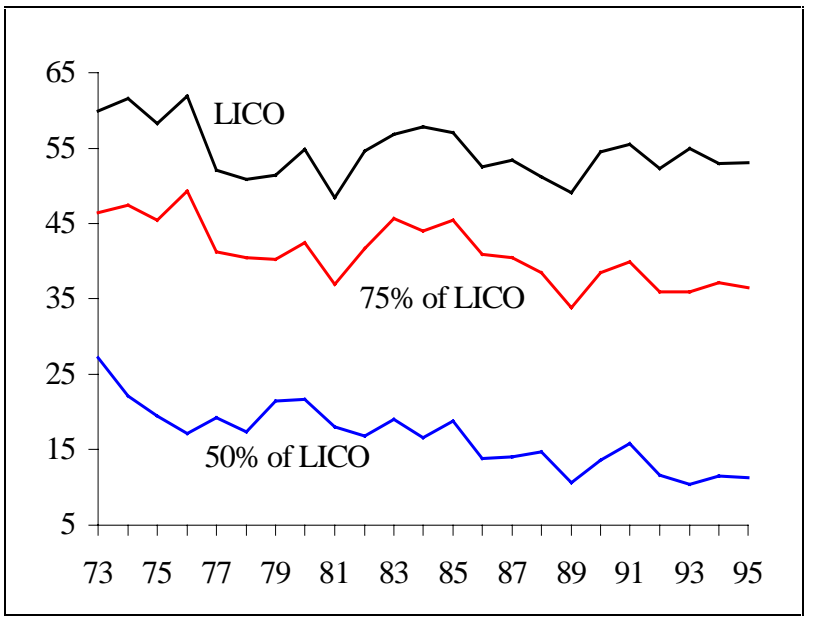


Breaking down by decades, low income rates decreased markedly during the 1970s for all types of families. But since the early 1980s, these rates have shown little evidence of decline; and for some types of families, they have actually increased.

The decline in low income using lower cut-offs was much stronger for many families. In 1973, $24.2 \%$ of unattached individuals possessed income which was less than $50 \%$ of the LICOs. By $1995,15.6 \%$ of these individuals fell below the $50 \%$ threshold. Similarly, $27.2 \%$ of lone parents had income which was less than the 50\% threshold in 1973, and this rate declined to $11.3 \%$ by 1995.

Transfers to many families have increased substantially over this period. Figure A in the appendix shows the trend in real per capita transfers to families from 1973 to 1995 . Transfers were nearly 2.5 times larger in 1995 than they were in 1973, with 66\% of this increase occurring after 1980. A study by Picot and Myles (1996) examined the period from 1973 to 1991 finding that only a small portion of the rise in transfers to poor families with children is the result of increased EI transfer income. They report that 'most of the increase in transfer payments to low income families was associated with greater dependence on child benefits and social assistance' (p.249). Increased transfer income over the period has more than offset declining earnings for low income families, leaving the rates of low income within each family type somewhat lower in 1995 than it was in 1973.

\subsection{What are the Relationships?}

To examine the relationships between economic performance, transfers and low income among families in Canada, we estimate the following reduced form pooled cross-section time-series model:

$$
\mathrm{LIR}_{\mathrm{it}}=\beta_{0}+\beta_{1} \text { PERFORM }_{\mathrm{it}}+\beta_{2} \text { TRANSFER }_{\mathrm{it}}+\mu_{\mathrm{it}}
$$

where $\mathrm{LIR}_{\mathrm{it}}=$ low income rate for families in period $\mathrm{t}$ for province $\mathrm{i}$;

PERFORM $_{i t}=$ the employment-population ratio in period $t$ for province $\mathrm{i}$;

TRANSFER $_{i t}=$ transfers per capita (hundreds of dollars) in period $\mathrm{t}$ for province $\mathrm{i}$; and

$\mu_{\mathrm{it}}=$ error term.

To take advantage of the substantial variations across provinces, the data are pooled over the 10 provinces for 23 years, leading to a total of 230 observations for estimation for each of the 5 family types. Equation 1 is estimated using low income rates calculated for three different thresholds: $100 \%$ of the LICOs, $75 \%$ of the LICOs and $50 \%$ of the LICOs. 


\section{Table 1}

Estimated Coefficients on Low Income Rates among non-Elderly Canadian Families: Basic Models

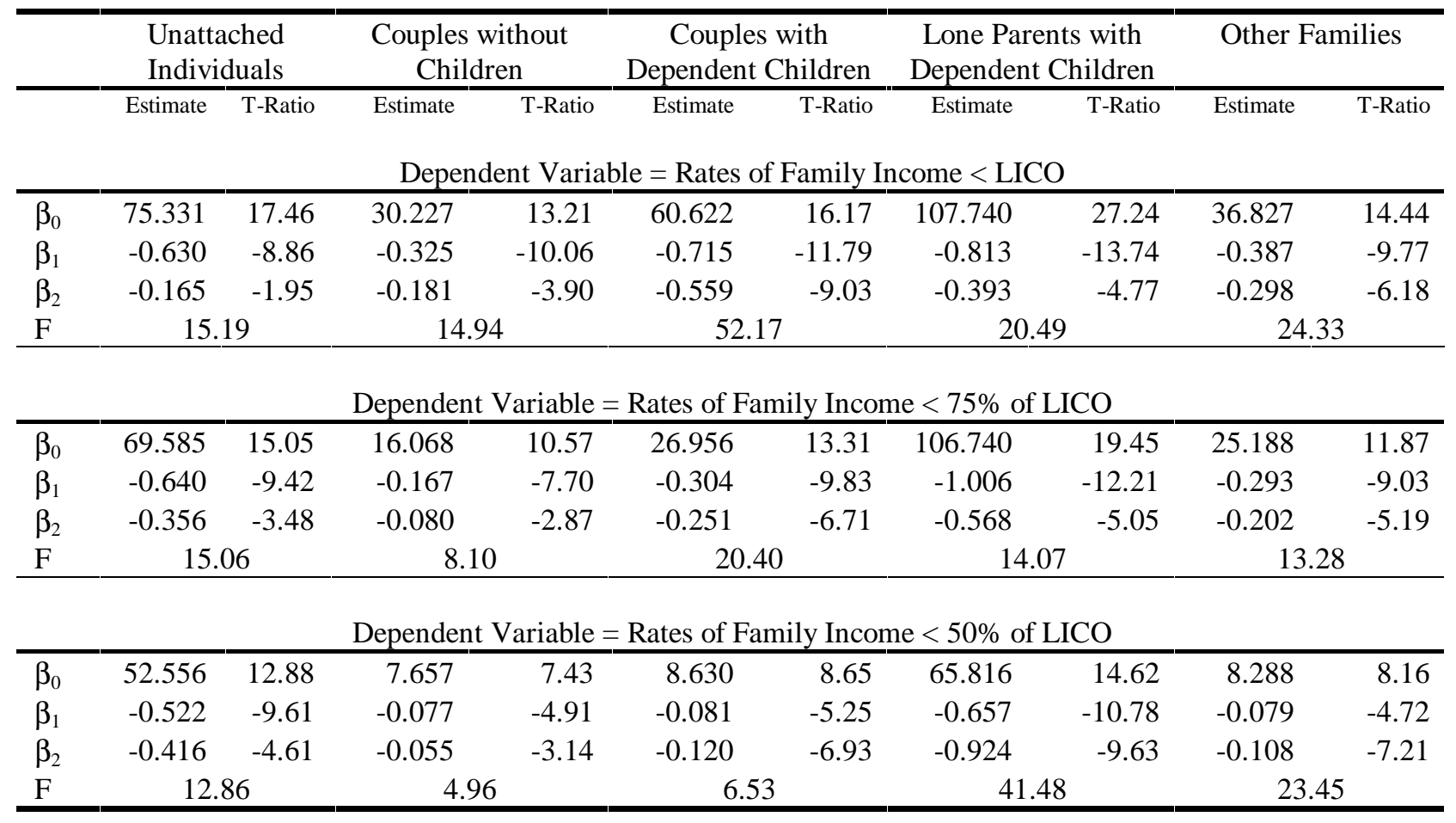

The regression results for Equation 1 are presented in Table $1 .^{6}$ These estimates show that there is a negative relationship between economic performance and low income rates. Also, an increase in per capita transfers is associated with a reduction in low income. These results hold for each family type and for all three different measures of low income. For the purpose of exposition, we concentrate on results for LICOs.

The estimated results show that a 1 percentage point increase in the employment-population ratio is associated with a 0.63 percentage point reduction in the low income rate for unattached individuals, a 0.72 percentage point reduction for couples with children and 0.81 percentage point reduction for lone parents. A larger estimated $\beta_{1}$ coefficient, in absolute terms, for a particular family type does not necessarily mean that improved economic performance has a stronger impact on low income rate reduction for that family type. Using the mean values for low income rates in Table A of the appendix as a scaling factor, we see that the 0.63 percentage point reduction in low income rates for unattached individuals is equivalent to a $1.7 \%$ decline (i.e., -0.63/37.91) in their low income rate; a 5.5\% decline for couples with children; and, a 1.4\% decline for lone parent families.

${ }^{6}$ The full pooled model of cross-section and time-series is estimated, which assumes the error term is correlated across provinces and autoregressive over time. See Kmenta (1986: 622-25) for details. 
An increase in government transfers is also associated with a reduction in the incidence of low income for these families. A $\$ 100$ increase in per capita transfers is expected to reduce the low income rate by 0.17 percentage points for unattached individuals, 0.56 percentage points for couples with children and 0.39 percentage points for lone parents with children. ${ }^{7}$

In short, an expanding economy has played an important role in reducing low income rates among families. Increasing transfers are also found to have reduced low income rates among families. However, these results represent the average relationships among these variables from 1973 to 1995. It is important to know if these relationships have strengthened or weakened over time.

\subsection{Have the Relationships Changed?}

The period since the early 1980s has been characterized by deteriorating labour market conditions such as rising unemployment rates, a relative and absolute decline in earnings of youth and the stagnation of family income (e.g., Sharpe and Zyblock (1996); Zyblock (1996); Morissette, Myles and Picot (1994)). Numerous explanations have been advanced to describe the underlying causes of these outcomes. More commonly cited explanations include the effects of altered patterns of international trade and globalized competition, skill-biased technological change and firm level down-sizing. ${ }^{8}$ Although there is no consensus regarding the causes, there is a general agreement that some form of structural change has occurred.

We incorporate the effects of structural change into our model. Arguably, the effects of structural change on family outcomes are revealed by examining the time path of the Gini coefficient measured on a pre-transfer basis. ${ }^{9}$ Market income inequality has shown an upward trend from 1973 to 1995 for unattached individuals, couples without children, and couples with children (Figure 3). Gini-measured inequality was nearly identical at the endpoints for lone parent families and decreased somewhat over the period for other families. Upon closer inspection, the figure reveals a sharp increase in the Gini coefficient starting around 1980 for each family type. These trends are consistent with the hypothesis that structural changes occurred in the early 1980 s.

${ }^{7}$ To examine the sensitivity of the results to different measures of economic performance, Equation 1 is also estimated using the unemployment rate and GDP per capita. The results based on the unemployment rate are qualitatively similar. These results are robust irrespective of the threshold or the family type. The coefficient on the transfer variable remained statistically significant and carried a negative sign throughout most regressions. Transfers were found to be statistically insignificant when GDP per capita was used. However, the coefficient on GDP per capita carried a negative and statistically significant sign throughout all regressions.

${ }^{8}$ A collection of recent research by various contributing authors dealing with structural change in the Canadian labour market is found in Abbott, Beach and Chaykowski (1997). The results of these studies point to a marked change in the trends of several labour market indicators starting in the late 1970s or early 1980s such as an increase in the probability of being employed for short duration, and increasing unemployment rates. Similar findings on change in job tenure are found in Heisz (1996).

${ }^{9}$ The time path of the distribution of market income reflects reorganizations taking place in financial markets and, more importantly, the labour market. Any significant shifts in the economy that act to widen the distribution of market income will be concealed by an offsetting change in government transfer payments. This is why we prefer to use the pre-transfer (or, market) income Gini coefficient in the analysis as opposed to the posttransfer income Gini coefficient. 
Figure 3

\section{Gini Coefficients Calculated from pre-Transfer Family Income}

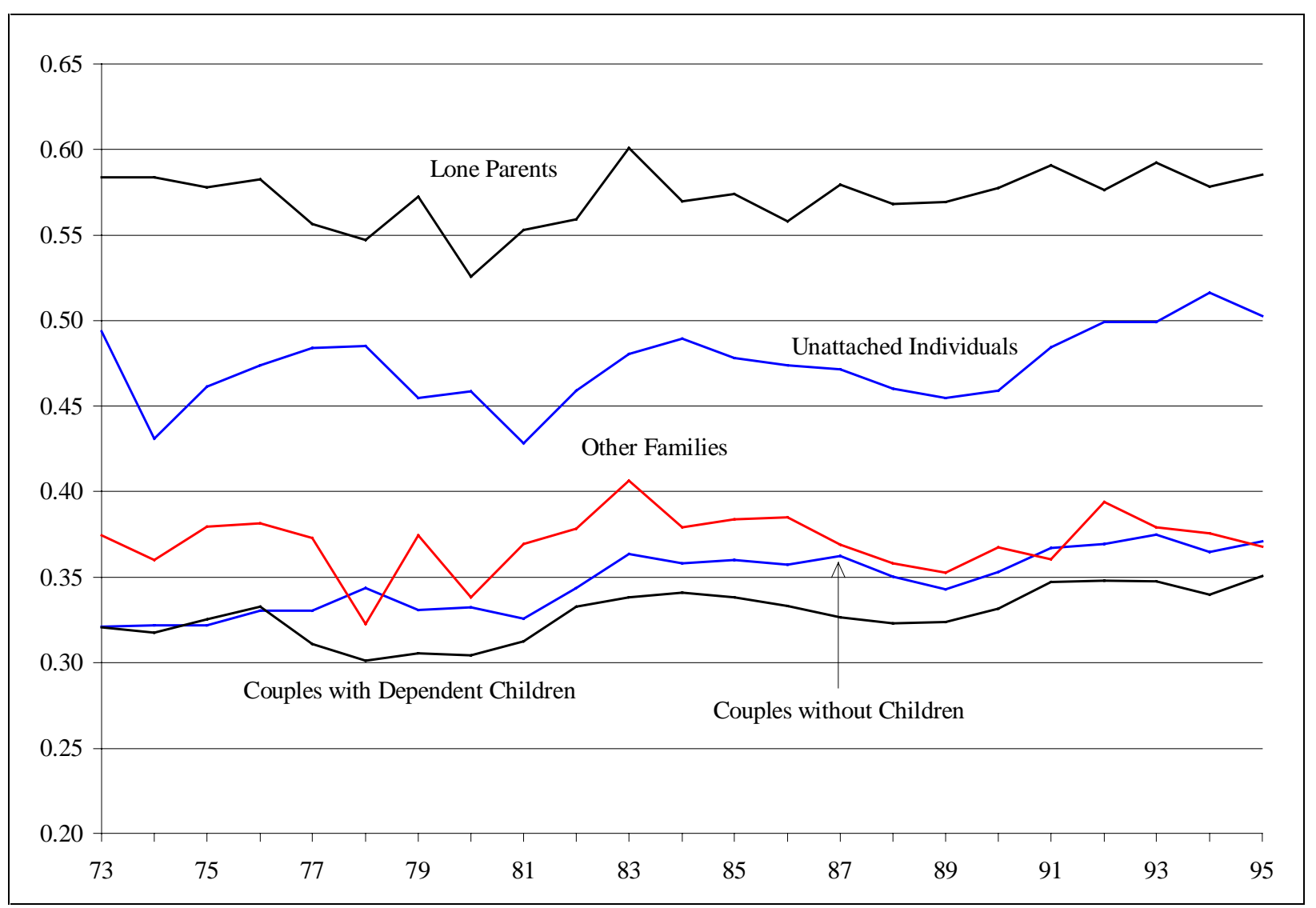

The approach we undertake permits us to 1) verify whether inequality among families interferes with the mechanisms that translate improved economic performance (or increased transfers) into reductions in low income; and 2) see if the increase in inequality, especially after 1980 for all families, contributed to a deterioration in the strength of the relationship between improved economic performance (or increased transfers) and low income reduction.

We therefore reformulate our model such that these relationships are time-varying. That is,

$$
\operatorname{LIR}_{\mathrm{it}}=\beta_{0}+\beta_{1 \mathrm{t}} \text { PERFORM }_{\mathrm{it}}+\beta_{2 \mathrm{t}} \text { TRANSFER }_{\mathrm{it}}+\epsilon_{\mathrm{it}} .
$$

In other words, the coefficients on PERFORM and TRANSFER are explicitly modeled as a function of the Gini coefficient:

$$
\begin{aligned}
& \beta_{1 \mathrm{t}}=\theta_{1}+\theta_{2} \mathrm{GINI}_{\mathrm{it}} \\
& \beta_{2 \mathrm{t}}=\gamma_{1}+\gamma_{2} \mathrm{GINI}_{\mathrm{it}} .
\end{aligned}
$$


Substitution of $2 \mathrm{a}$ and $2 \mathrm{~b}$ into Equation 2 yields Equation 3 for estimation:

$$
\begin{aligned}
\text { LIR }_{\mathrm{it}}= & \beta_{0}+\theta_{1} \text { PERFORM }_{\mathrm{it}}+\theta_{2} \text { PERFORM }_{\mathrm{it}}{ }^{*} \text { GINI }_{\mathrm{it}} \\
& +\gamma_{1} \text { TRANSFER }_{\mathrm{it}}+\gamma_{2} \text { TRANSFER }_{\mathrm{it}}{ }^{*} \text { GINI }_{\mathrm{it}}+\epsilon_{\mathrm{it}}
\end{aligned}
$$

where GINI $_{i t}=$ market income Gini coefficient in period $t$ for province $\mathrm{i}$; All other variables are the same as in Equation 1.

A widening distribution of income among families is expected to moderate the effects of improved economic performance and increased transfers on low income. Thus, we expect $\theta_{2}>0$ and $\gamma_{2}>0$.

Table 2

Estimated coefficients on Low Income Rates among non-Elderly Canadian Families:

\begin{tabular}{|c|c|c|c|c|c|c|c|c|c|c|}
\hline & \multicolumn{2}{|c|}{$\begin{array}{l}\text { Unattached } \\
\text { Individuals }\end{array}$} & \multicolumn{2}{|c|}{$\begin{array}{l}\text { Couples without } \\
\text { Children }\end{array}$} & \multicolumn{2}{|c|}{$\begin{array}{c}\text { Couples with } \\
\text { Dependent } \\
\text { Children }\end{array}$} & \multicolumn{2}{|c|}{$\begin{array}{l}\text { Lone Parents with } \\
\text { Dependent Children }\end{array}$} & \multicolumn{2}{|c|}{ Other Families } \\
\hline & Estimate & T-Ratio & Estimate & T-Ratio & Estimate & T-Ratio & Estimate & T-Ratio & Estimate & T-Ratio \\
\hline \multicolumn{11}{|c|}{ Dependent Variable $=$ Rates of Family Income $<$ LICO } \\
\hline$\beta_{0}$ & 61.728 & 17.79 & 28.230 & 14.40 & 50.066 & 15.50 & 84.351 & 19.40 & 27.617 & 9.51 \\
\hline$\theta_{1}$ & -0.953 & -9.38 & -0.495 & -8.69 & -1.003 & -12.75 & -1.044 & -6.96 & -0.453 & -5.86 \\
\hline$\theta_{2}$ & 1.334 & 6.68 & 0.689 & 5.11 & 1.495 & 7.86 & 1.161 & 5.10 & 0.596 & 3.56 \\
\hline$\gamma_{1}$ & -1.434 & -3.23 & -0.796 & -3.93 & -0.492 & -1.95 & -1.661 & -3.21 & -0.667 & -2.22 \\
\hline$\gamma_{2}$ & 2.037 & 2.28 & 1.256 & 2.32 & -0.424 & -0.59 & 1.918 & 2.32 & 1.080 & 1.40 \\
\hline $\mathrm{F}$ & \multicolumn{2}{|c|}{102.92} & \multicolumn{2}{|c|}{71.11} & \multicolumn{2}{|c|}{78.89} & \multicolumn{2}{|c|}{90.61} & \multicolumn{2}{|c|}{48.33} \\
\hline \multicolumn{11}{|c|}{ Dependent Variable $=$ Rates of Family Income $<75 \%$ of LICO } \\
\hline$\beta_{0}$ & 56.266 & 16.23 & 15.840 & 9.63 & 19.579 & 14.27 & 80.044 & 12.81 & 17.763 & 8.71 \\
\hline$\theta_{1}$ & -0.992 & -9.99 & -0.268 & -5.47 & -0.505 & -12.79 & -0.896 & -4.97 & -0.247 & -4.20 \\
\hline$\theta_{2}$ & 1.365 & 7.39 & 0.379 & 3.39 & 1.094 & 10.97 & 0.726 & 2.87 & 0.242 & 1.81 \\
\hline$\gamma_{1}$ & -1.473 & -3.49 & -0.462 & -2.71 & -0.400 & -2.93 & -3.311 & -4.86 & -0.566 & -2.48 \\
\hline$\gamma_{2}$ & 1.772 & 2.07 & 0.743 & 1.56 & 0.122 & 0.31 & 4.254 & 4.00 & 0.968 & 1.62 \\
\hline $\mathrm{F}$ & \multicolumn{2}{|c|}{105.61} & \multicolumn{2}{|c|}{28.61} & \multicolumn{2}{|c|}{107.41} & \multicolumn{2}{|c|}{66.33} & \multicolumn{2}{|c|}{32.58} \\
\hline \multicolumn{11}{|c|}{ Dependent Variable $=$ Rates of Family Income $<50 \%$ of LICO } \\
\hline$\beta_{0}$ & 47.767 & 14.70 & 6.802 & 5.76 & 6.269 & 8.94 & 60.879 & 11.31 & 6.084 & 5.41 \\
\hline$\theta_{1}$ & -0.785 & -7.88 & -0.089 & -2.53 & -0.144 & -6.51 & -0.512 & -3.81 & -0.077 & -2.03 \\
\hline$\theta_{2}$ & 0.884 & 4.62 & 0.138 & 1.69 & 0.368 & 5.83 & -0.063 & -0.28 & 0.091 & 0.99 \\
\hline$\gamma_{1}$ & -1.829 & -4.32 & -0.466 & -3.68 & -0.371 & -5.67 & -2.654 & -4.73 & -0.198 & -1.35 \\
\hline$\gamma_{2}$ & 2.247 & 2.62 & 0.880 & 2.51 & 0.533 & 2.82 & 2.836 & 2.95 & 0.269 & 0.70 \\
\hline $\mathrm{F}$ & \multicolumn{2}{|c|}{82.18} & & & \multicolumn{2}{|c|}{59.07} & 39 & & \multicolumn{2}{|c|}{8.79} \\
\hline
\end{tabular}
Models with Interaction

Table 2 presents the regression results for Equation 3. The direct effect of economic performance on low income is captured by $\theta_{1}$, which is negative and statistically significant throughout all regressions. As expected, the joint effect of economic performance and inequality on low income, $\theta_{2}$, is positive and significant in most cases. 
Similarly, the direct effect of transfers on low income, captured by $\gamma_{1}$, is negative and statistically significant throughout all models except for other families. And, in most cases, increasing inequality reduces the ability of transfers to lift families above the low income threshold, i.e., $\gamma_{2}$ is positive and statistically significant.

What the model has shown up to this point is that inequality does interfere with the mechanisms linking improved economic performance, increased transfers, and low income reduction. However, to determine if the relationships have changed over time we estimate the $\beta \mathrm{s}$ in each year for economic performance (Equation 2a) and transfers (Equation 2b) using estimates presented in Table 2 and the actual Gini coefficients. These dynamics are shown in Figure 4 for the models using the LICOs as the low income threshold. ${ }^{10}$ These results indeed demonstrate that the effects of economic performance on low income reduction have weakened for unattached individuals, couples without children, and families with children over the entire period of 1973 to 1995, but have not changed for lone parents and other families.

Let's turn to the developments since the early 1980s. Between 1981 and 1995, the time-varying economic performance coefficient became $26 \%$ smaller in absolute terms (from -0.382 to -0.282 ) for unattached individuals; $11.8 \%$ smaller (from -0.271 to -0.239) for couples without children; $10.6 \%$ smaller (from -0.536 to -0.479 ) for couples with children; $9.5 \%$ smaller (from -0.402 to -0.364) for lone parents; and remained unchanged (at -0.233) for other families. The coefficient on the transfer variable also became less negative after 1980 for unattached individuals, couples without children, and lone parent families. ${ }^{11}$

In summary, the relationship between economic performance and low income weakened over the entire period from 1973 to 1995 for most families, and after 1980 for all families. Similar patterns are observed for transfers. These declines in the effectiveness of economic performance and transfers in lifting family income above the LICOs are due to rising inequality.

${ }^{10}$ The evolution of the $\beta$ s over time is similar for the two lower thresholds.

${ }^{11}$ At the $5 \%$ level of significance, $\gamma_{2}$ is not significantly different from zero for couples with children and other families. For this reason, the coefficient on the transfer variable is reported as a horizontal line in Figure 4 for these two family types. 
Figure 4

Estimated Effects of Economic Performance and Transfers on Rates of Family Income < LICO, 1973-1995

A: Unattached Individuals

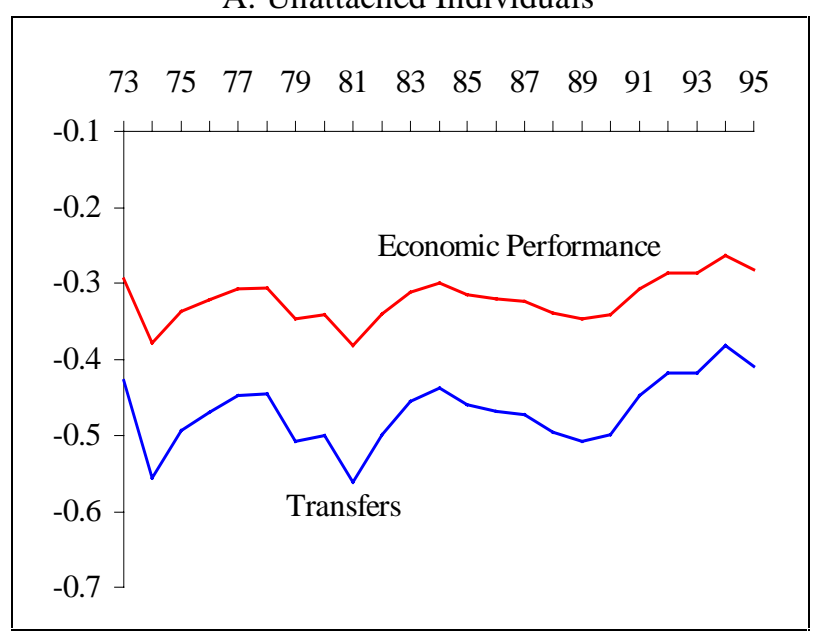

C: Couples with Dependent Children

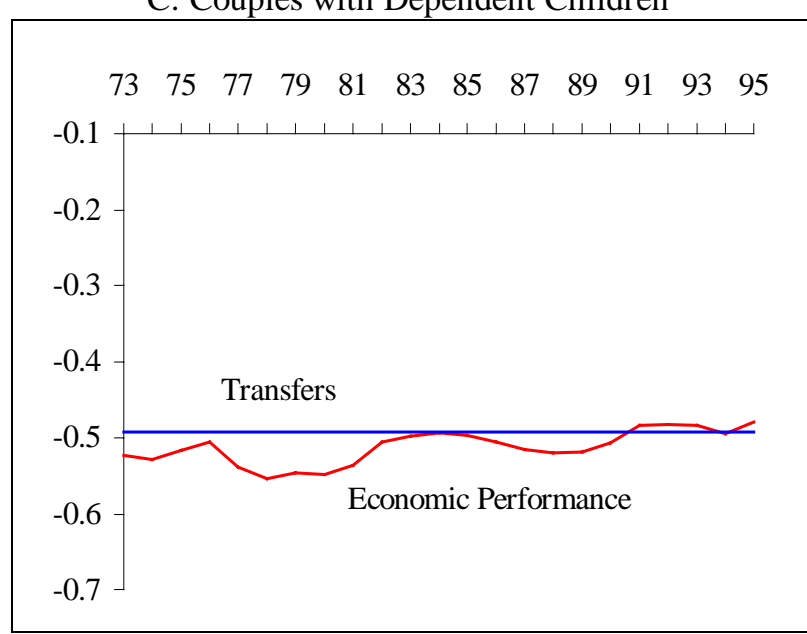

E: Other Families

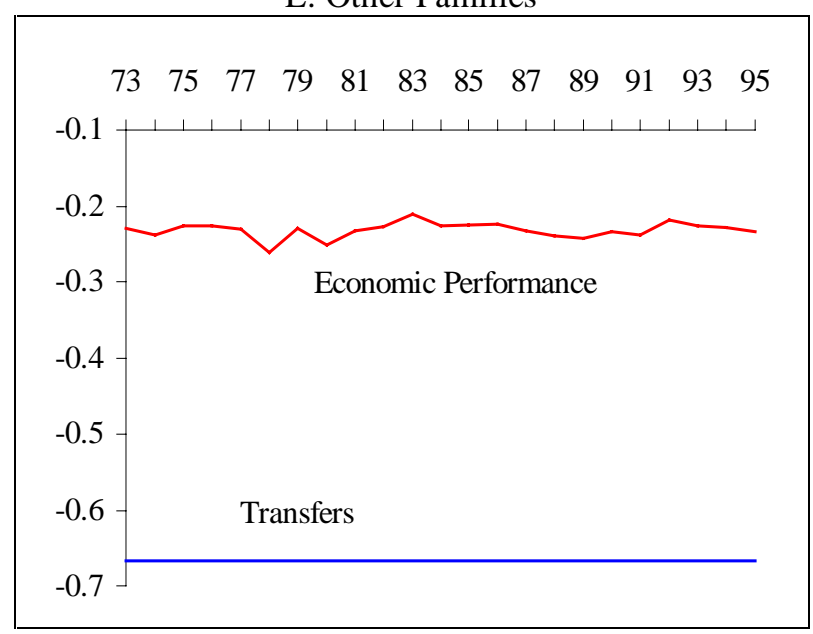

B: Couples without Children

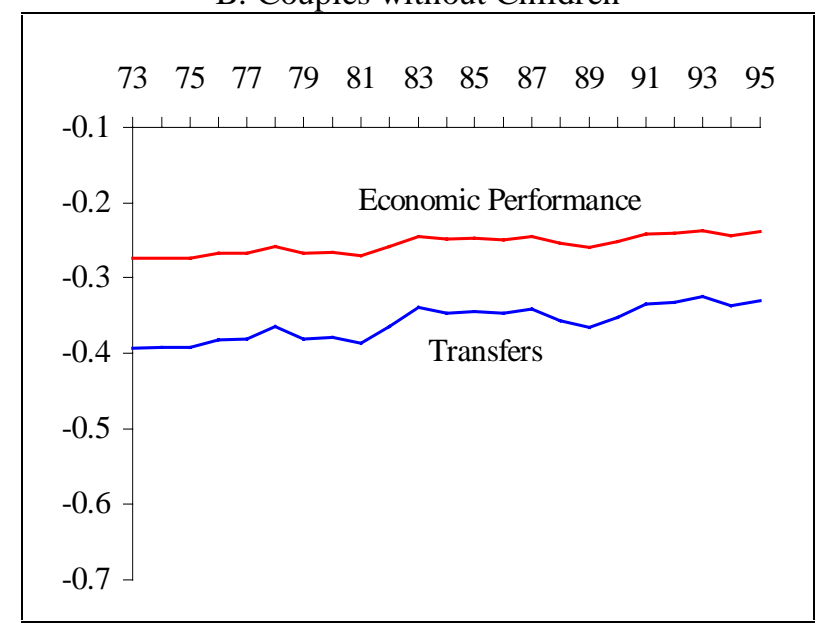

D: Lone Parents

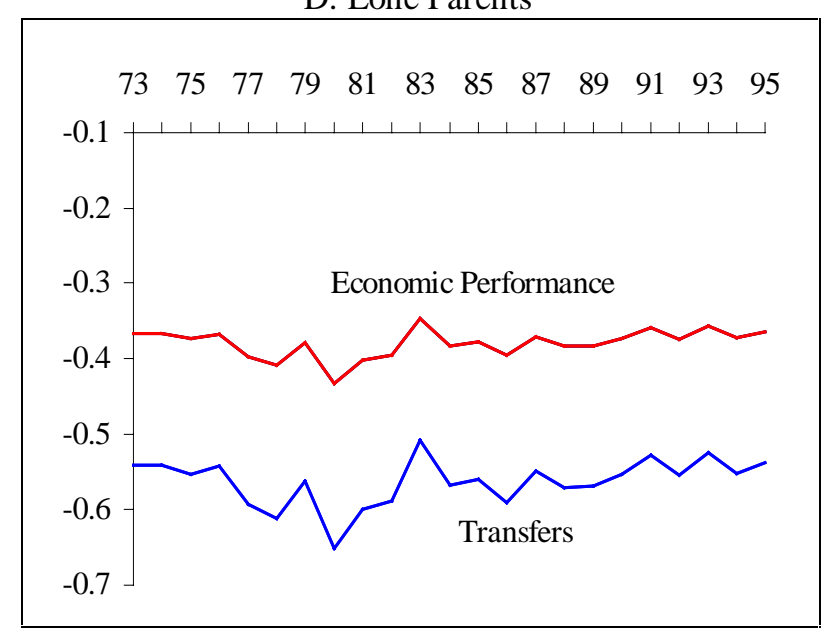




\section{Concluding Remarks}

We return to the question posed in the title of this paper: Trickling down or fizzling out? Our analysis, which examines the period from 1973 to 1995, shows that economic performance has had an important influence on reducing low income among Canadian families. These results are robust for all five family types examined and for three different measures of low income. Thus, it appears that families located near the bottom of the income distribution benefit from improved economic performance --- growth continues to trickle down. These findings are consistent with recent Canadian (e.g., Perron and Vaillancourt, 1988) and American (e.g., Tobin, 1994; Azam and Redmon, 1993; Blank and Card, 1993) studies. However, this relationship has generally weakened for most families from 1973 to 1995, and for all families since 1980, because of increasing income inequality --- the effectiveness of growth is fizzling out. This is consistent with most of the recent US literature (e.g., Smolensky et al, 1994; Azam and Redmon, 1993; Blank and Card, 1993). So, it appears that an improving economy is important for reducing low income. But, the effectiveness of improved economic performance on low income reduction ultimately depends on how the gains from expansion are distributed. 


\section{Appendix}

Figure A

Trends in Key Variables
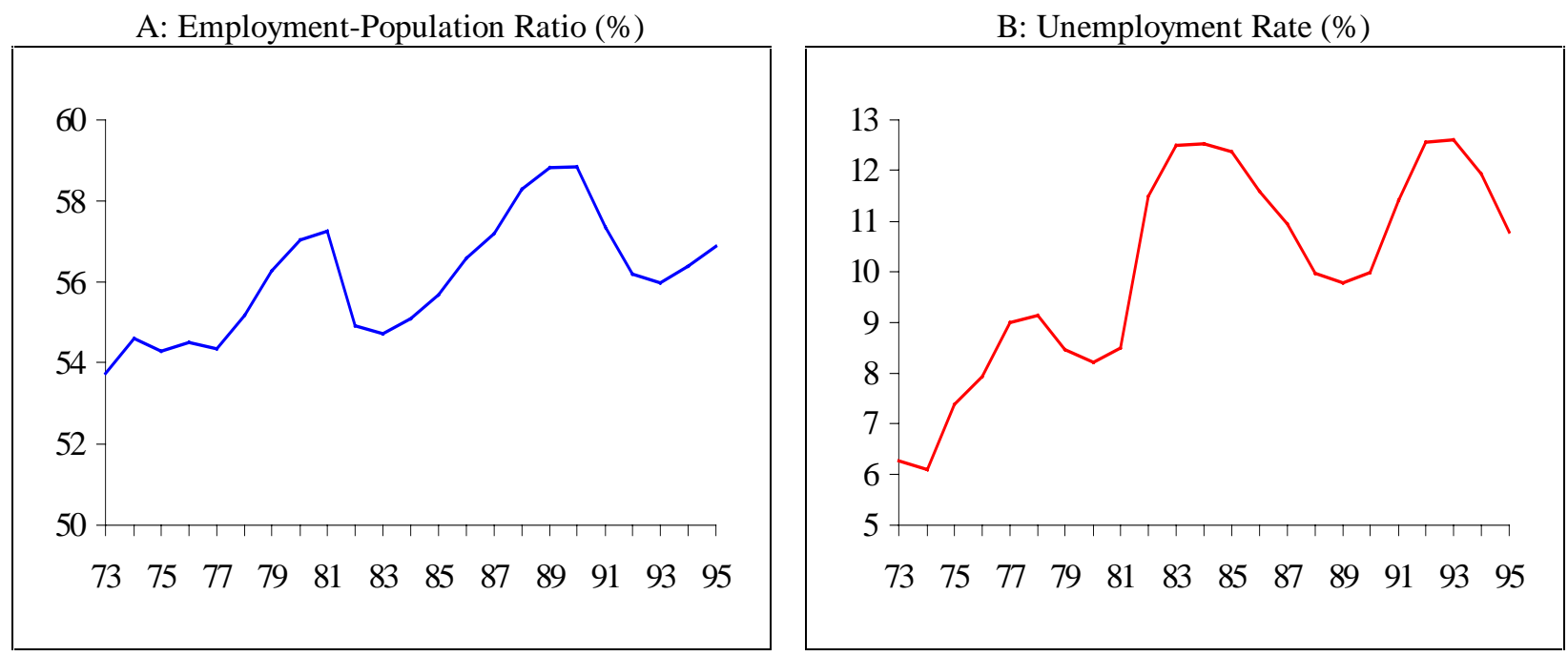

C: Per-Capita GDP (Thousands of 1992 Dollars)

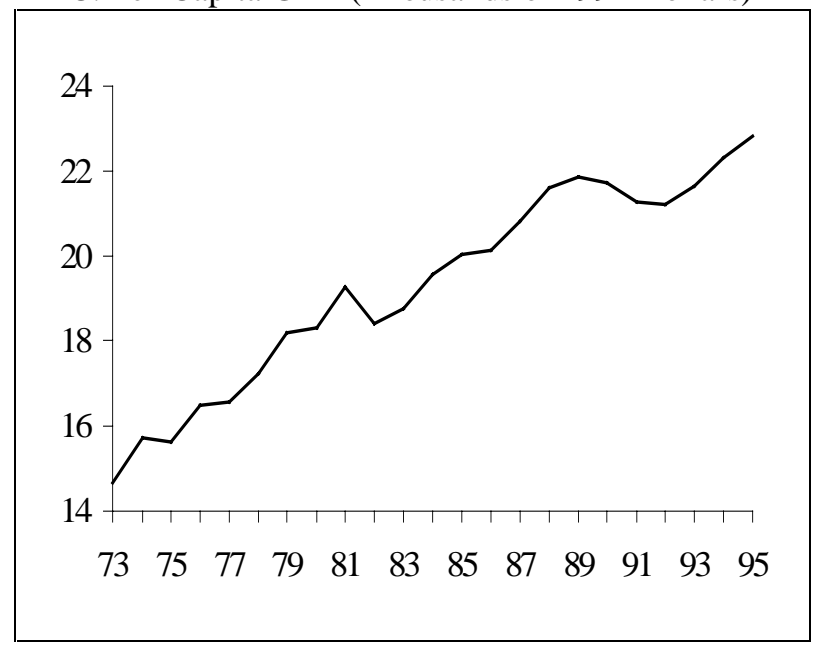

D: Indexed Per-Capita Transfers $(1973=100)$

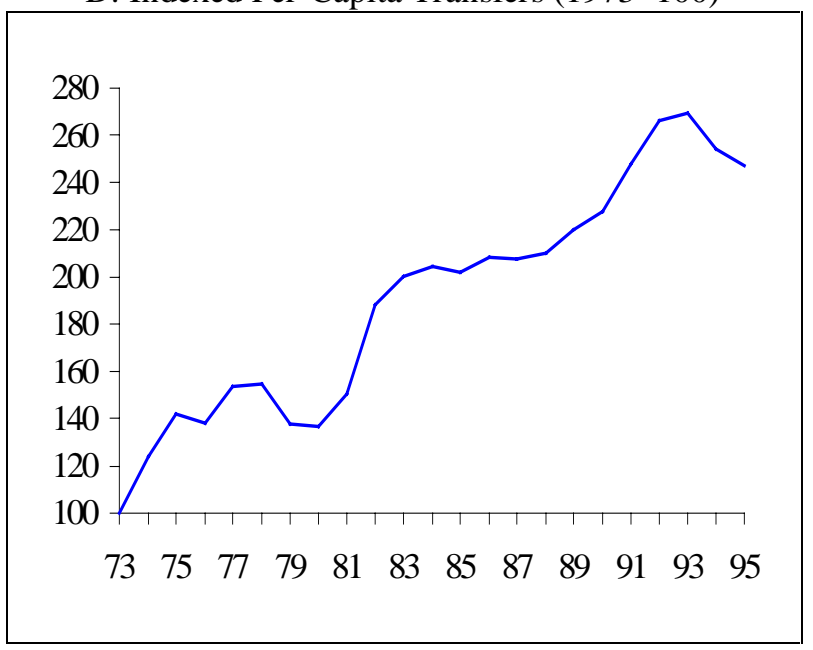


Table A

Sample Means and Standard Deviations

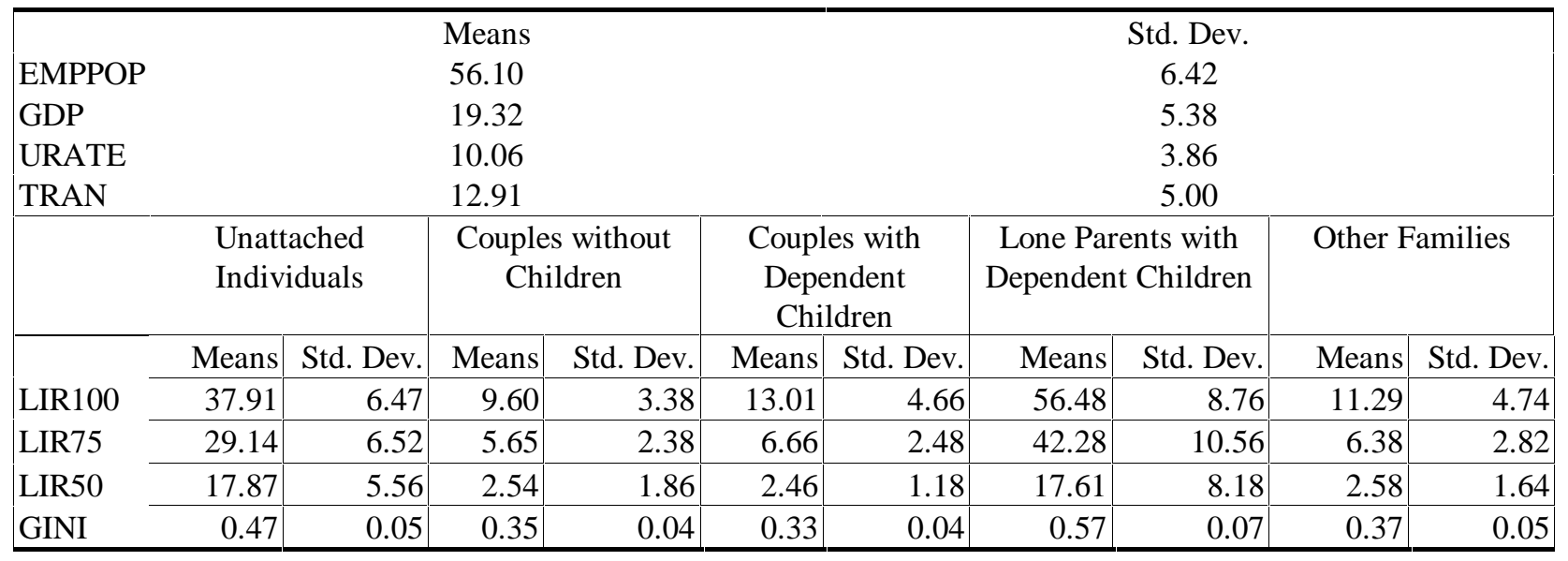

Note: $\quad$ EMPPOP = Employment-population ratio (\%);

GDP $=$ Per-capita gross domestic product (thousands of 1992 constant dollars);

URATE $=$ Unemployment rate $(\%)$;

TRAN $=$ Per-capita government transfers to persons (hundreds of 1992 constant dollars);

LIR100 $=$ Rate of family income $<$ LICO $(\%)$

LIR75 = Rate of family income $<75 \%$ of LICO (\%);

LIR50 = Rate of family income $<50 \%$ of LICO (\%); and

GINI $=$ Gini coefficients calculated from pre-transfer family income. 


\section{Selected References}

Abbott, Michael G., Charles M. Beach and Richard P. Chaykowski (Ed, 1997). Transition and Structural Change in the North American Labour Market, Kingston, Ontario: IRC Press.

Anderson, W.H. Locke (1964); "Trickling Down: The Relationship Between Economic Growth and the Extent of Poverty Among American Families", Quarterly Journal of Economics, November.

Azam, Golam and Alonzo Redmon (1993). "Revisiting the Relationship between Growth and Poverty", Review of Black Political Economy, vol. 22(1), Summer.

Blank, Rebecca M. and Alan S. Blinder (1986). "Macroeconomics, Income Distribution and Poverty", in Fighting Poverty: What Works and What Doesn't, eds. Sheldon Danziger and Daniel Weinberg, Harvard University Press.

Blank, Rebecca M. and David Card (1993). "Poverty, Income Distribution and Growth: Are they Still Connected?", Brookings Papers on Economic Activity, 2.

Cutler, David M. and Lawrence F. Katz (1991). "Macroeconomic Performance and the Disadvantaged", Brookings Papers on Economic Activity, 2.

Danziger, Sheldon and Peter Gottschalk (1986). "Do Rising tides Lift All Boats? The Impact of Secular and Cyclical Changes on Poverty", American Economic Review, vol. 76(2), May.

Gottschalk, Peter and Sheldon Danziger (1985). "A Framework for Evaluating the Effects of Economic Growth and Transfers on Poverty", American Economic Review, vol. 75(1), March.

Heisz, Andrew (1996). "Changes in Job Tenure and Job Stability in Canada", Statistics Canada: Analytical Studies Branch Research Paper Series No. 95.

Kmenta, J. (1986), Elements of Econometrics, 2nd Edition, New York: Macmillan.

Morissette, R., J. Myles and G. Picot (1994). "Earnings Inequality and the Distribution of Working Time in Canada", Canadian Business Economics, Spring.

Osberg, Lars (1996). "Economic Growth, Income Distribution and Economic Welfare", presented at the Annual American Economic Association Meetings, New Orleans, January 5, 1997.

Perron, Pierre and François Vaillancourt (1988). "The Evolution of Poverty in Canada, 19701985”, Economic Council of Canada, Discussion Paper \#343, February. 
Picot, Garnett and John Myles (1996). "Social Transfers, Changing Family Structure and Low Income Among Children", Canadian Public Policy, vol. 22(3).

Sharpe, Andrew and Myles Zyblock (1996). "Macroeconomic Performance and Income Distribution in Canada", presented at the Annual Meeting of the American Economic Association, New Orleans, January 4-7, 1997.

Smolensky, Eugene, Robert Plotnick, Eirik Evenhouse and Siobhan Reilly (1994). "Growth, Inequality and Poverty: A Cautionary Note", Review of Income and Wealth, series 40(2), June.

Tobin, James (1994). "Poverty in Relation to Macroeconomic Trends, Cycles, and Policies", in Confronting Poverty: Prescriptions for Change, eds. Sheldon H. Danziger, Gary D. Sandefur, and Daniel H. Weinberg, Institute for Research on Poverty.

Zyblock, Myles (1996). "Individual Earnings Inequality and Polarization: An Exploration into Population Sub-Group Trends in Canada, 1981 to 1993", Human Resources Development Canada: Applied Research Branch Working Paper \#W-96-8E. 